\title{
Necessidade de tratamento periodontal avaliada pelo CPITN e sua relação com a qualidade de acabamento cervical das restaurações
}

\section{Need for periodontal treatment evaluated through CPITN and its relation to the quality of the cervical margin of restorations}

\author{
Getúlio da Rocha NOGUEIRA-FILHO* \\ Cristine M. STEFANI* \\ Márcio Z. CASATI* \\ Celina M. NAKAI** \\ Carla A. S. PLAZA** \\ Francisco H. NOCITI Jr.*** \\ Enilson A. SALLUM*** \\ Sérgio de TOLEDO****
}

\begin{abstract}
NOGUEIRA-FILHO, G. da R.; STEFANI, C. M.; CASATI, M. Z.; NAKAI, C. M.; PlAZA, C. A. S.; NOCITI Jr., F. H.; SALLUM, E. A.; TOLEDO, S. de. Necessidade de tratamento periodontal avaliada pelo CPITN e sua relação com a qualidade de acabamento cervical das restaurações. Pesqui Odontol Bras, v. 15, n. 1, p. 51-55, jan./mar. 2001.

Irregularidades do acabamento cervical de restaurações constituem fatores de retenção de placa bacteriana, dificultando o controle de placa pelos procedimentos habituais de higiene bucal, favorecendo o desenvolvimento da doença periodontal. O objetivo deste estudo foi avaliar as condições periodontais e a necessidade de tratamento em função do acabamento cervical de restaurações dentais. Foram examinados 367 dentes restaurados com classes II e V de amálgama, classe III em resina, restauração metálica fundida e próteses unitárias. Utilizando-se sonda periodontal (OMS), verificou-se a posição do término da restauração (supragengival, subgengival ou ao nível da margem gengival); a qualidade das restaurações (falta ou excesso de material restaurador) e a presença de grau 2 do CPITN. Após a análise dos dados, foi possível concluir que: 1) o término supragengival ofereceu a melhor adaptação marginal e a menor freqüência de grau 2 do CPITN; 2) a falta ou excesso de material restaurador favorecem o desenvolvimento de grau 2, independentemente do material utilizado e 3) nos términos subgengivais, foi maior a freqüência de adaptação marginal incorreta, principalmente casos de excesso de material restaurador, sendo estes casos de maior ocorrência de grau 2 do CPITN.
\end{abstract}

UNITERMOS: Doenças periodontais; Adaptação marginal; CPITN

\section{INTRODUÇÃO}

Durante muito tempo, atribuiu-se ao cálculo dental a etiologia da doença periodontal ${ }^{13,21}$. Entretanto, estudos epidemiológicos ${ }^{18}$ vieram provar que o agente primário causador da doença periodontal não era o cálculo dental e sim a placa bacteriana. LÖE et al. ${ }^{12}$ (1965) comprovaram que o acúmulo de placa bacteriana estava intimamente relacionado com o desenvolvimento de gengivite. Dessa forma, a placa bacteriana foi considerada fator etiológico primário da doença periodontal. Algumas condições, tais como depósitos dentais mineralizados (cálculo supra- e subgengival), margens de restau- rações desadaptadas (tanto o excesso quanto a falta de material restaurador), próteses e lesões cariosas não tratadas, contribuem secundariamente ao desenvolvimento da doença periodontal ${ }^{3}$. Estudos microscópicos demonstraram que todos esses fatores atuam como retentores de placa, tanto dificultando o controle mecânico pelos métodos usuais de higiene bucal, quanto favorecendo o acúmulo de placa bacteriana ${ }^{12}$. Vários estudos demonstraram que irregularidades no acabamento cervical de restaurações constituem fatores de retenção de placa bacteriana dos mais significativos e freqüentes ${ }^{4,5,11,15,17,19}$, levando ao desenvolvimento

\footnotetext{
* Doutores em Clínica Odontológica, Área de Periodontia da Faculdade de Odontologia de Piracicaba da UNICAMP.

** Cirurgiãs-Dentistas.

*** Professores Associados; ****Professor Titular - Área de Periodontia da Faculdade de Odontologia de Piracicaba da UNICAMP.
} 
NOGUEIRA-FILHO, G. da R.; STEFANI, C. M.; CASATI, M. Z.; NAKAI, C. M.; PLAZA, C. A. S.; NOCITI Jr., F. H.; SALLUM, E. A.; TOLEDO, S. de. Necessidade de tratamento periodontal avaliada pelo CPITN e sua relação com a qualidade de acabamento cervical das restaurações. Pesqui Odontol Bras, v. 15, n. 1, p. 51-55, jan./mar. 2001.

dos processos inflamatórios gengivais e do aparelho de inserção periodontal, classificados como gengivite e periodontite ${ }^{6}$, respectivamente. Considerando-se os fatores de retenção de placa bacteriana, as alterações periodontais e o tratamento periodontal, alguns indices foram desenvolvidos para possibilitar uma maior orientação clínica ao cirurgião-dentista ${ }^{7,14,16}$. Seguindo essa premissa, a Organização Mundial da Saúde (OMS) introduziu o Índice Comunitário de Necessidade de Tratamento Periodontal (CPITN) - que apresenta ao clínico indicações sobre a necessidade de tratamento periodontal $^{1,2,20}$. Logo, este trabalho teve por objetivo, aplicando os critérios do CPITN, estudar as condições periodontais e a necessidade de tratamento, em função da adaptação cervical das restaurações dentais.

\section{MATERIAL E MÉTODO}

Foram examinados 367 dentes apresentando restaurações dos tipos: classes II, III e V, coroas totais e RMF (restaurações metálicas fundidas), utilizando-se uma sonda periodontal preconizada pela OMS, para a identificação das irregularidades existentes no limite cervical das restaurações dentais examinadas. Foram considerados: (1) posição do término - supra, subgengival ou ao nível cervical; (2) adaptação cervical da restauração - falta ou excesso de material restaurador e (3) existência ou não do grau 2 do CPITN associado ao dente examinado. Durante o exame, foram selecionados ape-

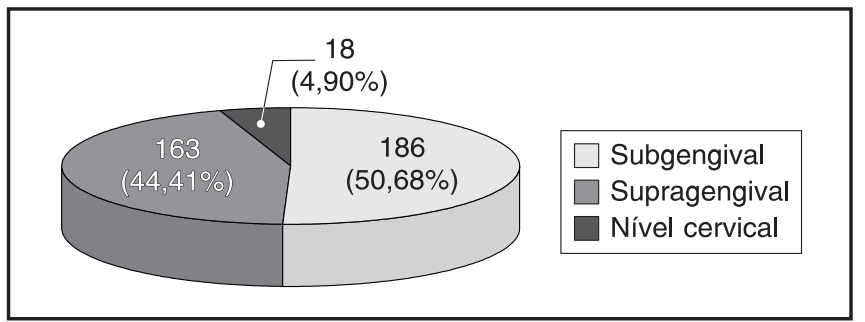

GRÁFICO 1 - Restaurações examinadas quanto ao término cervical.

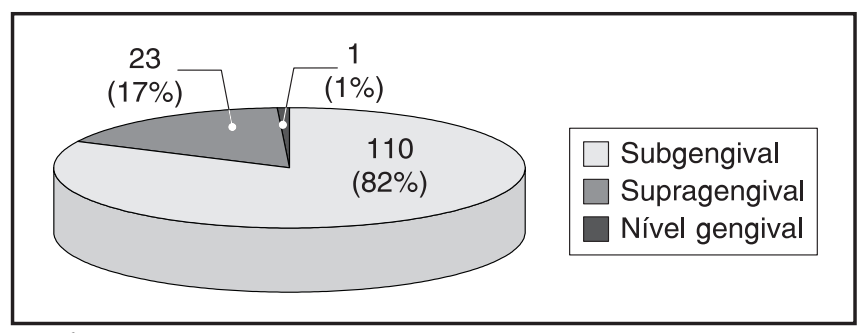

GRÁFICO 2 - Sítios com inflamação gengival (graus 1 e 2 do CPITN) quanto ao término cervical. nas quatro dentes de cada voluntário. Cada dente foi examinado e classificado isoladamente conforme o tipo de restauração, de material, término cervical, adaptação cervical e o grau 2 do CPITN. Esse trabalho visou a prevalência do grau 2 do CPITN, cujo tratamento periodontal compreenderia raspagem e polimento dental profissional, acompanhado de educação do paciente para higiene bucal e controle de placa bacteriana.

\section{RESULTADOS}

Das 367 restaurações examinadas, 64,85\% eram classes II de amálgama, 14,71\% classes III de resina composta, $11,72 \%$ coroas totais, $4,63 \%$ RMF e 4,09\% classes V de amálgama ou resina composta. Destas, 50,68\% (186) estavam localizadas subgengivalmente, 44,41\% (163) eram supragengivais e 4,91\% (18) ao nível da margem gengival (Gráfico 1). De todas as restaurações examinadas, 194 (52,86\%) apresentavam imperfeições marginais (falta ou excesso de material restaurador). Destas, 67\% eram subgengivais e 77,84\% apresentavam excesso de material restaurador. Das 367 restaurações examinadas, 134 (36,52\%) apresentavam inflamação gengival. Destas, 82,09\% (110) eram subgengivais (Gráfico 2) e 85,82\% (115) apresentavam grau 2 do CPITN, ou seja, inflamação gengival associada a falta ou excesso de material restaurador. Das 115 restaurações com grau 2 , um total de 97 (84,34\%) eram subgengivais. Das restaurações subgengivais examinadas, 38\% apresentava excesso ou falta de material restaurador (Gráfico 3) e destas, 75\% apresentavam grau 2 do CPITN (Gráfico 4). Já as restaurações supragengivais examinadas estavam com a adaptação marginal correta em sua maioria (69\%) e apenas $6 \%$ (Gráfico 5) delas apresentavam inflamação gengival (grau 2 do CPITN). As incorretas (falta ou excesso de material restaurador), que corresponderam a $38 \%$ das restaurações supragengivais ainda assim apresentaram menor freqüência de grau 2 do CPITN (29\%). Avaliando apenas as restaurações de

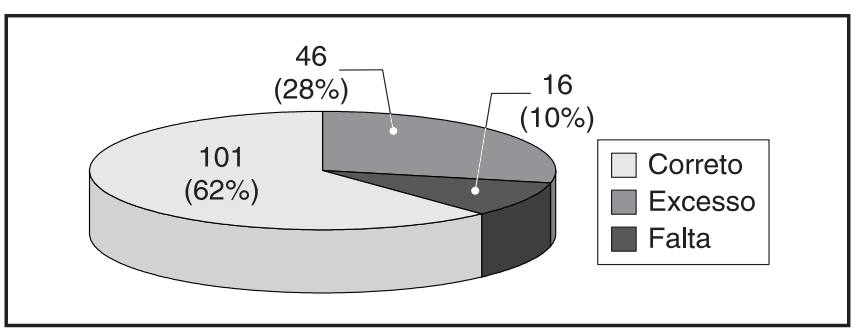

GRÁFICO 3 - Restaurações subgengivais quanto a qualidade da adaptação cervical. 
NOGUEIRA-FIlHO, G. da R.; STEFANI, C. M.; CASATI, M. Z.; NAKAI, C. M.; PlAZA, C. A. S.; NOCITI Jr., F. H.; SALlUM, E. A.; TOLEDO, S. de. Necessidade de tratamento periodontal avaliada pelo CPITN e sua relação com a qualidade de acabamento cervical das restaurações. Pesqui Odontol Bras, v. 15, n. 1, p. 51-55, jan./mar. 2001.

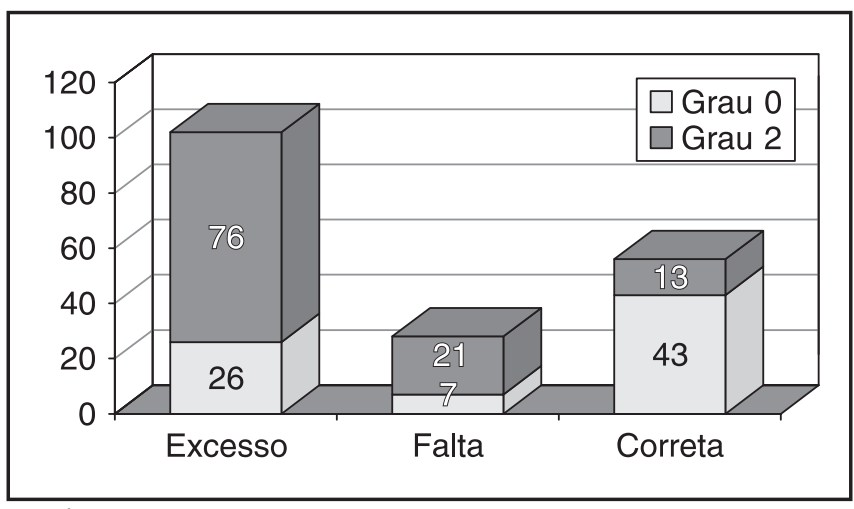

GRÁFICO 4 - Restaurações subgengivais quanto ao grau do CPITN.

amálgama, encontramos 253 ao todo, sendo $53,36 \%$ subgengivais, $41,9 \%$ supragengivais e $4,74 \%$ ao nivel da margem gengival. As que apresentavam falta ou excesso de material restaurador foram $59,68 \%$, sendo que destas $70,68 \%$ eram falta e $29,32 \%$ eram excesso de material. Das 253 restaurações examinadas 43,87\% apresentavam inflamação gengival, sendo que destas $81,98 \%$ estavam posicionadas subgengivalmente, $88,29 \%$ apresentavam falta ou excesso de material restaurador (grau 2 do CPITN) e 73,87\% eram subgengivais com defeito de adaptação marginal.

\section{DISCUSSÃO}

Este trabalho procurou avaliar a relação entre os procedimentos restauradores e os tecidos periodontais, destacando a importância do término cervical quanto a qualidade da adaptação cervical e sua relação com a presença de doenças periodontais. Quanto ao tipo de término cervical, a maioria das restaurações encontravam-se subgengivalmente $(50,68 \%)$, sendo estas também as que apresentaram a maior porcentagem de imperfeições quanto à adaptação marginal $(52,86 \%)$.

ARNEBERG et al. ${ }^{4}$ (1980) analisaram 314 restaurações de amálgama classe II, das quais 58\% eram subgengivais. De todas as restaurações observadas $50 \%$ apresentavam defeitos marginais, sendo os excessos de material os mais encontrados $(71,5 \%)$. Já o estudo conduzido por LEON ${ }^{11}$ (1976), em que foram examinadas 2.888 restaurações classes II de amálgama, 50,77\% estavam posicionadas subgengivalmente. Destas, $74 \%$ apresentavam imperfeições marginais. As restaurações com excesso ou falta de material apresentaram maiores índices gengivais do que as restaurações sem irregularidades cervicais, independentemente

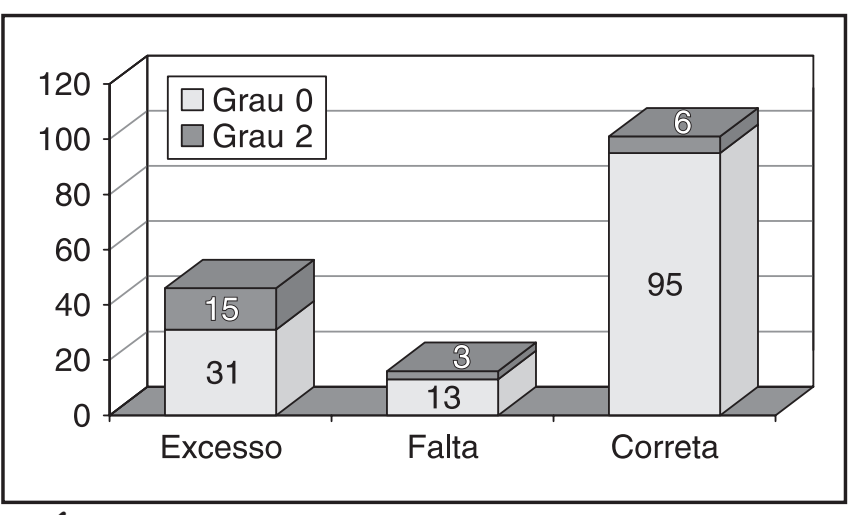

GRÁFICO 5 - Restaurações supragengivais quanto ao grau do CPITN.

da posição das margens. Tais resultados estão de acordo com o presente estudo, em que foram analisadas 253 restaurações de amálgama classe II, das quais $53,36 \%$ eram subgengivais e $59,68 \%$ apresentavam imperfeições marginais. Das imperfeições, 29,32\% eram excessos marginais e $70,86 \%$ estavam posicionadas subgengivalmente. Apesar disso, está comprovado na literatura ${ }^{5,8}$ que restaurações com desadaptações cervicais são achados freqüentes na clínica, principalmente naquelas com limite cervical abaixo da margem gengival. Restaurações com desadaptações estão intimamente relacionadas com alterações periodontais, tais como inflamação gengival ${ }^{3,8,9}$, perda de inserção $0^{3,8,11,23}$, reabsorção óssea e lesões de bifurcação ${ }^{23}$. Este processo patológico é decorrente do acúmulo de placa bacteriana em regiões onde o seu controle muitas vezes é impossivel de ser realizado; bem como de alterações na microbiota periodontal $^{10}$.

KARLSEN $^{8}$ (1970) avaliou, clínica e histologicamente, a reação do tecido gengival frente à utilização de restaurações supra- e subgengivais. A maioria dos sítios que tinham término subgengival apresentou inflamação gengival, sendo esta mais pronunciada nas restaurações com imprecisões marginais, indicando o importante papel das irregularidades cervicais e da rugosidade na retenção da placa bacteriana, fator etiológico da doenças periodontais.

Em nosso estudo, foi utilizado o Índice Comunitário de Necessidade de Tratamento Periodontal (CPITN) para identificação de sítios com inflamação gengival; sítios com sangramento à sondagem em restaurações com adaptação marginal correta, independentemente da posição do término cervical receberam a classificação de grau 1 do CPITN; sí- 
NOGUEIRA-FILHO, G. da R.; STEFANI, C. M.; CASATI, M. Z.; NAKAI, C. M.; PlAZA, C. A. S.; NOCITI Jr., F. H.; SALLUM, E. A.; TOLEDO, S. de. Necessidade de tratamento periodontal avaliada pelo CPITN e sua relação com a qualidade de acabamento cervical das restaurações. Pesqui Odontol Bras, v. 15, n. 1, p. 51-55, jan./mar. 2001.

tios com sangramento à sondagem em restaurações com adaptação marginal defeituosa, independentemente da posição do término cervical receberam a classificação de grau 2 do CPITN.

Analisando-se os resultados, percebe-se que quanto à adaptação marginal, o grau 2 do CPITN predominou onde houve excesso de material restaurador. Quanto à posição do término cervical, o grau 2 do CPITN foi mais freqüente nas restaurações subgengivais do que nas supragengivais, dados estes que estão de acordo com a literatura revista $^{3,8,9}$. Mas não apenas restaurações com imperfeições cervicais estão associadas a patologias periodontais. Altos índices de inflamação gengival foram relatados para situações em que as restaurações subgengivais se apresentavam bem adaptadas $^{8,11}$, pois criam condições propícias para a proliferação de microrganismos periodontais patogênicos ${ }^{15}$. No presente estudo, ao contrário, 76,8\% das restaurações subgengivais bem adaptadas não tinham sangramento à sondagem (grau 0 do CPITN), demonstrando que estas restaurações não influenciaram o desenvolvimento de gengivite. Apesar da pequena freqüência de grau 2 do CPITN encontrada nas restaurações subgengivais com adaptação marginal correta, não se justifica a realização de restaurações subgengivais, porque a confecção de próteses e restaurações subgengivais com adaptação marginal correta é tecnicamente muito dificil, e, dessa forma, as interfaces dente-restauração rapidamente tornam-se preenchidas por placa bacteriana, em uma região onde o controle mecânico não é efetivo com escovas e mé- todos de higiene interdentais, favorecendo recidivas de cárie e contribuindo para um processo inflamatório periodontal ${ }^{22}$. O tratamento do grau 2 do CPITN envolve a remoção dos agentes retentores da placa bacteriana. A correção das margens da restauração, combinada ao controle efetivo de placa, reduz significativamente a inflamação gengival e deve ser parte da terapia inicial. No presente estudo, 36,51\% das restaurações apresentavam inflamação gengival (graus 1 ou 2 do CPITN), cujos procedimentos de tratamento devem estar no domínio do clínico geral. Diante dessa situação, é fundamental que o profissional, ao realizar qualquer tipo de procedimento restaurador, tenha conhecimento e domínio da técnica e dos tecidos periodontais, procurando avaliar sempre, não apenas a estética e função oclusal do paciente, como também os limites biológicos dos tecidos, já que foi demonstrado por diversos estudos que todos esses procedimentos restauradores podem ser considerados fatores predisponentes ao desenvolvimento de patologias periodontais.

\section{CONCLUSÕES}

1. O término cervical supragengival apresentou menor freqüência do grau 2 do CPITN que os demais tipos de término.

2. O grau 2 do CPITN predominou em restaurações com término cervical subgengival e adaptação marginal incorreta, principalmente as que apresentaram excesso de material restaurador.

NOGUEIRA-FILHO, G. da R.; STEFANI, C. M.; CASATI, M. Z.; NAKAI, C. M.; PLAZA, C. A. S.; NOCITI Jr., F. H.; SALLUM, E. A.; TOLEDO, S. de. Need for periodontal treatment evaluated through CPITN and its relation to the quality of the cervical margin of restorations. Pesqui Odontol Bras, v. 15, n. 1, p. 51-55, jan./mar. 2001.

Irregularities of the cervical margin of restorations facilitate the retention of bacterial plaque, hindering plaque control through the habitual procedures of oral hygiene and favoring the development of periodontal disease. The aim of this study was to evaluate the periodontal condition and treatment needs (applying CPITN) in relation to the cervical margin of dental restorations. Three hundred and sixty-seven teeth with class II and V cavities restored with amalgam, class III cavities restored with composite resin, cast metal restorations and unitary prostheses were examined. With a WHO periodontal probe, the position of the cervical margins of restorations was verified (supragingival, subgingival or at the gingival margin level); the presence of defects (lack or excess of restoring material) and the presence of score 2 of CPITN were also assessed. After the analysis of the data, it was possible to conclude that: 1) supragingival margins offered the best marginal adaptation and the lowest frequency of score 2; 2) both the lack and the excess of restoring material favor the development of score 2, despite the utilized material and 3) in subgingival margins, incorrect marginal adaptation was the most frequent event, mainly due to excess of restoring material, and in these cases there was higher frequency of score 2 of CPITN.

UNITERMS: Periodontal diseases; Marginal adaptation; CPITN. 
NOGUEIRA-FIlHO, G. da R.; STEFANI, C. M.; CASATI, M. Z.; NAKAI, C. M.; PlAZA, C. A. S.; NOCITI Jr., F. H.; SALlUM, E. A.; TOLEDO, S. de. Necessidade de tratamento periodontal avaliada pelo CPITN e sua relação com a qualidade de acabamento cervical das restaurações. Pesqui Odontol Bras, v. 15, n. 1, p. 51-55, jan./mar. 2001.

\section{REFERÊNCIAS BIBLIOGRÁFICAS}

1. AINAMO, J.; BARMES, D.; BEAGRIE, G. et al. Development of the World Health Organization (WHO) Community Periodontal Index of Treatment Needs (CPITN). Int Dent J, v. 32, n. 3, p. 281-291, 1982.

2. AINAMO, J. Public Health of Periodontal Disease. Assessment of periodontal treatment needs: adaptation of the WHO Community Periodontal Index of Treatment Needs (CPITN) to European countries. In: FRANDSEN, A. Berlin : Quintessence, 1984.

3. ALBANDAR, J. M.; BUISCHI, Y. A.; AXELSSON, P. Caries lesions and dental restorations as predisposing factors in the progression of periodontal diseases in adolescents: a 3-year longitudinal study. J Periodontol, v. 66, n. 4, p. 249-254, 1995.

4. ARNEBERG, P.; SILNESS, J.; NORDBO, H. Marginal fit and cervical extent of class II amalgam restorations related to periodontal condition: a clinical and roentgenological study of overhang elimination. J Periodontal Res, v. 15, n. 6, p. 669-677, 1980.

5. BJÖRN, A. L.; BJÖRN, H.; GRKOVIC, B. Marginal fit of restorations and its relation to periodontal bone level. Part I - metal fillings. Odontol Rev, v. 20, n. 3, p. 311-321, 1969.

6. GENCO, R. J. et al. Periodontia Contemporânea. São Paulo : Livraria Santos Editora, 1996.

7. JOHANSEN, J. R.; GJERMO, P.; BELLINI, H. T. A system to classify the need for periodontal treatment. Acta Odontol Scand, v. 31, n. 5, p. 297-305, 1973.

8. KARLSEN, K. Gingival reactions to dental restorations. Acta Odontol Scand, v. 28, n. 6, p. 895-904, 1970.

9. KESZTHELYI, G.; SZABO, I. Influence of class II amalgam fillings on attachment loss. J Clin Periodontol, v. 11, n. 2, p. 81-86, 1984.

10. LANG, N. P.; KIEL, R. A.; ANDERHALDEN, K. Clinical and microbiological effects of subgingival restorations with overhanging or clinically perfect margins. J Clin Periodontol, n. 10, n. 6, p. 563-578, 1983.

11. LEON, A. R. Amalgam restoration and periodontal disease. Brit Dent J, v. 140, n. 11, p. 377-382, 1976.
12. LÖE, H.; THEILADE, E.; JENSEN, S. E. Experimental gingivitis in man. J Periodontol, v. 36, n. 5, p. 177-187, 1965.

13. LÖVDAL, A.; ARNO, A.; WAERHAUG, J. Incidence of clinical manifestations of periodontal disease in light of oral hygiene and calculus formation. J Am Dent Assoc, v. 56, n. 1, p. 21-33, 1958.

14. MacPHEE, I. T. Periodontal scoring - a simple method of periodontal scoring is a basis for treatment planning in teaching hospitals and general practice. Dent Pract Dent Rec, v. 17, n. 8, p. 269-273, 1967.

15. MULLER, H. P. The effect of artificial crown margins at the gingival margin on the periodontal conditions in a group of periodontally supervised patients treated with fixed bridges. J Clin Periodontol, v. 13, n. 2, p. 97-102, 1986.

16. O'LEARY, T. J. The periodontal screening examination. $\mathbf{J}$ Periodontol, v. 38, n. 6, p. 617-624, 1967.

17. RODRIGUEZ-FERRER, H. J.; STRAHAN, J. D.; NEWMAN, H. N. Effects of gingival health of removing overhanging margins of subgingival amalgam restorations. J Clin Periodontol, v. 7, n. 6, p. 457-462, 1980.

18. RUSSEL, A. L. Some epidemiological characteristics of periodontal diseases in a series of urban population. $\mathbf{J}$ Periodontol, v. 28, suppl. 57, p. 286-293, 1957.

19. SORENSEN, S. E.; LARSEN, I. B.; JORGENSEN, K. D. Gingival and alveolar bone reaction to marginal fit of subgingival crown margins. Scand J Dent Res, v. 94, n. 2, p. 109-114, 1986.

20. TERVONEN, T.; AINAMO, J. Relative influence of calculus and overhangs of fillings on the frequency of score 2 of the CPITN. Community Dent Oral Epidemiol, v. 14, n. 3, p. 136-137, 1986.

21. WAERHAUG, J. Gingival pocket: anatomy, pathology, deepening and elimination. Odontol Tidsskr, v. 60, n. 1, p. 5-186, 1952. Supplementum 1.

22. WAERHAUG, J. Histologic considerations which govern where the margins of restorations should be located in relation to gingiva. Dent Clin North Am, v. 4, p. 161-176, 1960.

23. WANG, H. L.; BURGETT, F. G.; SHYR, Y. The relationship between restoration and furcation involvement on molar teeth. J Periodontol, v. 64, n. 4, p. 302-305, 1993.

Recebido para publicação em 04/01/99 Enviado para reformulação em 18/10/99 Aceito para publicação em 11/05/00 